\title{
The Difference of Effectiveness Between Online and Offline Class
}

\author{
Xinyue You $^{1 *,+}$, YuanyuanTan ${ }^{2,+}$, Liwen Yang ${ }^{3,+}$ \\ ${ }^{1}$ Nanjing Foreign Language School Xianlin Campus,Nanjing,Jiangsu 210046,China, 3379392915@qq.com \\ ${ }^{2}$ Changsha Yali High School, Changsha, Hunan 410000, China, 3536531597@qq.com \\ ${ }^{3}$ Hamden Hall Country Day School, Hamden ct 06517, USA \\ + They are all first authors.
}

\begin{abstract}
Due to the advanced technology, online classes provide students with the flexibility of studying in any place with wifi and enable students to connect with teachers far away. The convenience that online classes bring leads to the prediction that online classes would replace the traditional form of study, which is studying in a physical classroom. During the eruption of the pandemic COVID in 2020, schools in many parts of the world temporarily transferred from physical classes as the main way of teaching to online classes as the only way of teaching. Students' feedback towards the efficiency of online classes and physical classes would help improve the educational system. In this study, online questionnaires are distributed to students who both have the experience for physical courses and online lessons experience during COVID in 2020. Feedbacks are collected to compare the efficiency between online learning and offline teaching; factors that influence the efficiency difference are analyzed; suggestions are given for having better studying experience.
\end{abstract}

Keywords: pandemics, education, effectiveness

\section{INTRODUCTION}

Since the 1990s, the rapid development of modern information technology has brought great changes to people's learning methods. As a new teaching method based on Internet, network classroom teaching appears in people's vision. The universality of its coverage, the interactivity of teaching mode, the openness of the platform and the rapidity of information dissemination make it play an increasingly important role in the process of modern teaching, which has attracted extensive attention. Due to the impact of the epidemic in 2020, online courses began to be put into use on a large scale. However, after a long time of online teaching, both students and teachers have found that its efficiency and quality are far lower than offline teaching hours. Previous studies have shown that there are many factors affecting the quality of network teaching, such as teaching style, lack of supervision, self-control ability, stability of teaching platform and so on.Some of the previous scholars said "Students are generally dissatisfied with the learning effect of online courses, but mainly in communication and Q\&A.”, "Technical issues were found to be the most influential factor when it came to satisfaction with online classes" [1]. Most of them collect data and draw conclusions by issuing questionnaires, collecting data and analyzing them. A few people establish models or design experiments. Researchers often ignore one of the other factors affecting their online teaching. Therefore, we decided to collect data more comprehensively, consider the different effects of different factors, compare people's different learning modes of online and offline courses, and collect people's evaluation, so as to find out the factors affecting online teaching more comprehensively, so as to give more suggestions and improvement methods for online teaching in the future.

\section{AIM}

During the covid period due to the large scale of having online classes, both teachers and students start to pay serious attention to the effectiveness of online classes. There are many negative comments about the online classes. In our research, we want to find out what makes the effectiveness of online classes different from the one of physical classes. And by figuring out the effectiveness- 
influential factors, we would give suggestions to improve on those points. And we hope to help students increase their effectiveness in learning.

\section{METHOD}

we have designed a questionnaire to collect the answers. Online questionnaires were conducted in an application called WenjuanXin. Some questions in the questionnaire are based on the previous study, and the questionnaires were distributed randomly to high school students around us. (Samples are mainly from the city of Changsha, Hunan province and the city of Nanjing, Jiangsu province. A little portion of the sample are from the city of Shanghai, Shandong province, and Guangdong province, and those who study abroad) The online questionnaire consists of 21 questions in total. Question No.1-4 asks about basic personal information: gender, school category, and the class. Question No.5-8 is about students' preference between online teaching and offline teaching. Question 9-12 asks about some basic information about the online learning experience. Question 13-20 ask about the different studying hobbies and grades comparing between online classes and offline classes. Because we know many variables such as: age, gender, type of school will influence the effectiveness from online study. ${ }^{[2]}$ Question 21 is about suggestions for improvement of online courses. All those questions in the questionnaire are provided with multiple choices for students to choose the best one fit their thoughts. 166 data were collected as a result. we will use online application to analysis the data.

\section{SAMPLE}

The sample of our study are high school students from different gender, different grade, and study at different kind of school (regular high school, international high school, study aboard) The reason for choose the high school students as the sample is because they have all taken the online class during the COVID period, since they gradually form their own thoughts, their words are more credible than junior middle school students. Since we haven't go to university, it is hard for us to collect the data from the college students. We can easily get contact with high school students, so they are the most fixable choice to be the sample. Since they all have the experience of online class, it will be easier for them to recall the memory and answer the question in the questionnaire. Though the questions may somehow related to their personal privacy, but we will tell them this is just for scientific research, not for other purposes, so they can fill in the questionnaire at ease.

\section{PROCEDURE}

We design the questionnaire

We consider about the validity and reliability
We ask professor to estimate our questionnaire

We send it to our friends (They are in different province and study in different kind of school.)

Last step can make us collect the data randomly

We will analysis the data and set different controls group

We will get the conclusion

\section{DATA ANALYSIS}

In this part, we try to analysis the essay from two ways. Single questions and combined question analysis. Because we know there

\section{Q1. Gender}

Among all the 166 samples that we've collected, $36.14 \%$ of them are male, $63.86 \%$ of them are female.

\section{Q2. School categories}

Among all the 166 samples that we've collected, $63.25 \%$ of them are from regular high school in China, $28.31 \%$ of them are from international high school in China, $8.43 \%$ of them study aboard.

\section{Q3 and 4. Grade}

(1) regular high school \& international high school

Among all the 166 samples that we've collected, 152 of them study at regular high school and international high school. $19.08 \%$ of them are in the first grade, $30.92 \%$ of them are in the second grade, $50 \%$ of them are in the third grade.

(2) study aboard

Among all the 166 samples that we've collected,14 of them study abroad. $14.29 \%$ of them are in the first grade, $7.14 \%$ of them are in the second grade, $28.57 \%$ of them are in the third grade, $\% 0 \%$ percent of them are in the fourth grade.

Q5. Have you had the experience of online classes before the start of COVID period in 2020?

Among the 166 samples, $67.47 \%$ of them have the experience of online classes before the start of COVID period in 2020, 32.53\% of them have not, which means that a large part of them have the experience of online classes before, this indicates the Importance and popularity of online classes under the age of information.

Q6. Which kind of class do you prefer?

Among all the 166 samples we've collected, about $86.14 \%$ of them prefer to take offline classes, $13.86 \%$ of them prefer to take online classes. We can see that almost all the people prefer to take offline classes rather than online classes. So in the next few questions, we will ask 
them the reason for choosing whether online or offline classes.

Q7. ( For those who choose online) Why do you prefer this type of class chosen above?

Among the 166 samples, only 23 of them prefer to take online classes. Among these 23 people,

$78.26 \%$ percent of them think that they can watch the playback, and it will be easier for them to learn; $56.52 \%$ of them think online classes can reduce unnecessary social pressure, such as interacting with their classmates $; 73.91 \%$ of them think that they can take classes anytime, anywhere; $30.43 \%$ of them think that the teaching forms are more varied, which motivate them to focus more on the class; 21.74 of them think that they are forced to take online classes due to the epidemic so they have no choice. From the data we can see that most of the people choose to take online classes because of its convenience, people can take the courses without limitation

And they think it will be helpful for their study. Half of the people think that the social interaction will be reduces and create an easier and less pressure atmosphere for them to study.

Q8. ( For those who choose offline) Why do you prefer this type of class chosen above?

Among the 166 samples, 143 of them prefer to take offline classes. Among these 143 people,

$83.92 \%$ of them think that the learning atmosphere of offline class is stronger than online class, make them more concentrate on their study; $69.23 \%$ think that it is easy for them to communicate and interact with their classmates, so as to improve their social skill as well as solve their problems;67.13\% of them think offline classes are more regimented so they are less likely to be distracted; $69.93 \%$ of them think it is easier for them to communicate with teachers face to face and solve problems in time. According to the data, we can see that most of the people think learning atmosphere is a very important factor for them while studying, and almost 70 percent of the people think the strict administration will let them focus more and thus letting them become more efficiency; over half of them think interaction is a very important factor, either talking to classmates or talking to teachers. They think it can help them solving problems on time and it is good for their study. So for the people that prefer studying offline, high efficiency is a very import reason for them to choose this type of class.

Q9. What's the percentage of online classes you had between the time period of 2020.02 and 2020.06?

During the COVID period, $69.42 \%$ of the classes are done online. The rest of the class are taken offline. The reason for this $30 \%$ of the offline classes may be the lack of administration of the government in foreign countries and the improvement of epidemic situation in China causes people to go back to school for offline study.

Q10. How many hours of online classes did you have per day during your online studying?

For all the 166 samples, $6.02 \%$ of them study online for1 to 2hours; $8.43 \%$ of them study online for 2 to 3 hours ; $14.46 \%$ take 3 to 4 hours; $17.47 \%$ take 4 to5hours; $22.29 \%$ of them take 5 to 6hours; $31.33 \%$ of them take 6 hours and above. The percentage of the data is increasing. Most of the people take the online classes for 5 hours and above.

Q11.During what time of the day did you have online classes?

The data indicate that almost $78 \%$ students will taking online class during $8 \mathrm{am}$ to $5 \mathrm{pm}$. This period is conform to the normal period to having class when they have outline class. And the rest of $22 \%$ students said they have taken the online class during the unusual period.

Q12.Did your normal resting time get influenced by the online class time?

There are $23 \%$ students choose online class will influence their sleeping quality. Maybe the students who choose unusual class time before are the students who choose will influence their sleeping quality. There are $77 \%$ students choose the online class will not influence their sleep quality. We can rule out the influence of sleep fatigue and other factors on the quality of online courses for most students.

Q13Comparing to the school semester of 2019.22019.6, how did your grade change during the school semester of 2020.2-2020.6?

In the light of the above questions, the questions that are presented.

Although there are almost $45 \%$ students could get the same grade as they taking outline class. There are still almost $41 \%$ students got the lower grades and only $11 \%$ students will got the higher grade. Students indicate online class may be useful but it is low efficiency. ${ }^{[4]} \mathrm{We}$ cannot ignore the effect brought by online class.

Q14.What Is The Perception Of The Live Class And the Recorded Class In All?

The data showed that on average, 39\% percent of all online lessons were recorded and 61percent students will have live class. This is still a good way to encourage children to attend classes on time, rather than delaying them.

Q15. Which kind of class will you be more concentrated on?

The answers to this question were quite divided, with 10 percent saying online courses made them more 
focused, while 90 said offline courses made them more focused.

Q16. (those who choose online class) What do you think are the important reasons that will effect student's concentration during the offline classes?

The 17 students who chose to teach online said that whispering to their classmates affected the efficiency of the class, while the length of the offline course was the main reason that affected the quality of offline teaching

Q17. (those who choose offline class) What do you think are the important reasons that will effect student's concentration during the online classes?

Among the 149 people who chose outline courses to make them more focused, said that difficulties in communication with teachers and classmates, the lack of learning atmosphere;

their own self-discipline ability are the three main reasons

Q18.Which class do you prefer to take notes in?

$54 \%$ students said they take note for online class as same as same for outline class.38\%students prefer to taking note for the outline class.8\%students prefer to taking note for online class. This can indicate outline class can really help students to do better notes for the class. And maybe this can help to improve the quality of class.

Q19 and 20. What is the timely completion rate of your homework during offline courses?

What is the timely completion rate of your homework during online courses?

We can see that the number of people who always completed the homework on time decreased sharply, while the number of others who completed the homework in low frequency increased, which indicates that the online teaching cannot timely check the completion of homework exercises after class. This may be one of the reason that students got better grade in the outline class.

Q21. What do you think needs to be improved in online teaching?

Students think online class needs improve most urgently are increase the communication between teacher and classmate, increase the measures for supervise students, and enhance the stability of website are the most important things. We also find an essay mentions that students will prefer outline classes because such as lack of motivation, understanding of the material, decrease in communication levels between the students and their instructors and their feeling of isolation caused by online classes. ${ }^{[3]}$

\subsection{Associated Data}

(1) The percentage of those who have experience in online teaching before 2020 also believe that online courses can make people pay more attention are less than those who don't have experience in online teaching before 2020 but also believe that online courses can make people pay more attention

By comparing the data from question 5"Have you had the experience of online classes before the start of COVID period in 2020?" and question 15"Which kind of class will you be more concentrated on?", we can see that among the 166 samples collected, 112 people had experience in online teaching before the epidemic, but only 11 people thought that online teaching could make them pay more attention, accounting for only $9.8 \%$ of the total. There were 54 people who are without online teaching experience, and 9 of them thought that online teaching could make them pay more attention, accounting for $16.6 \%$ of the total, which is higher than those with online teaching experience. This shows that the previous experience of online teaching makes the students have a deeper understanding of online teaching, so that they can better understand the defects of online teaching or their own shortcomings than those who have no experience of online teaching before, and this may be the reason why they don't think online classes are good for their concentration.

( 2 ) Though some people have online teaching experience before 2020, they still have lower grades than that of the period of offline class

By comparing the data from question 5"Have you had the experience of online classes before the start of COVID period in 2020?" and question 12 "Comparing to the school semester of 2019.2- 2019.6, how did your grade change during the school semester of 2020.2-2020.6?", we can see that among the 166 samples that we collected, 68 people thought their grades became lower and 55 of them had experience in online teaching before the epidemic, and it is about $80.8 \%$ percent of all the people who response their grades became lower. The percentage is extremely higher than those who didn't have the experience in online teaching and have a lower grade than before. It can be seen that even if some people had the experience of online class before, it is still not enough to help some students maintain the stability of their grades, and may even lead to the decline of their grades. This may be because in their previous experience, these students found the defects and difficulties of online teaching, like I've mentioned in the previous comparison, but they did not choose to overcome these difficulties on their own or feedback these defects to the school. Instead, they relied on these experiences to exploit loopholes and think of some side-by-side ways to reduce their pressure in class, this kind of mentality and behavior causes them to be more slack, and thus causes their grades to be strongly 
influenced, which makes their grade decline more severely than those without previous experience, plays an opposite role.

(3) The people who have always or often completed their homework on time when taking offline classes mostly always or often completed their homework on time when taking online classes.

By comparing the data from question 19 "What is the timely completion rate of your homework during offline courses ? " and question 20 "What is the timely completion rate of your homework during online courses ?" and find the people who response "Always" and " Often" for both two questions, we can see that in all the 166 samples, 151 students said they always or often complete their homework on time when they take offline courses, but the number of students who always or often complete their homework on time when they take online courses is less than those who take offline classes, 122 students response that they always or often complete their homework on time when they take online courses. It means that online courses will make the people without supervision and good self-control ability to stop complete their homework on time .However , 117 of the students complete their homework on time no matter which kind of class did they take, and it's almost cover all the students who often or always finish their homework on time in online and offline courses. (about $95.6 \%$ of the students who always or often complete their homework on time when they take online courses, $77.4 \%$ of the students who always or often complete their homework on time when they take offline courses) This shows that whether online or offline classes, students with good habits will insist on doing their homework, and the completion rate of homework will not be reduced because they take online classes. Since they have well self-controlled ability, their efficiency will not be affected.

\section{(4) Gender}

Gender is also an influential factor for the different effectiveness between the online classes and the offline classes. According to the data, the frequency of always and often completing hw on time is the most obvious change. The percentage of females who always and often complete hw on time drops up to $30 \%$ from $89.6 \%$ (59.4\% $+30.2 \%)$ to $68.8 \%(37.7 \%+31.1 \%)$ when the classes switched from offline to online. For male students, the percentage of always completing homework on time drops $11.6 \%$ from $93.3 \%(53.3 \%+40 \%)$ to $81.7 \%(40 \%$ $+41.7 \%)$. We can see from the chart that female students experienced a larger decrease in the rate of completing hw than male students.

\section{(5) Grade}

The different effectiveness between online learning and offline learning varies from different grades. The sample size for 9 th grade students is too small to come with a accurate conclusion, so that we want to focus more on the other grades. The percentage of 10th grade students who always and often complete hw on time drops 3.3\%, from $83.3 \%(50 \%+33.3 \%)$ to $80 \%(43.3 \%+36.7 \%)$. For the 11 th graders, the percentage decreased $21.6 \%$ from $98.1 \%(56.9 \%+41.2 \%)$ to $76.5 \%(39.2 \%+37.3 \%)$. To those who are in 12th grade, the percentage drops $20.6 \%$ from $89.2 \%(60.2 \%+29 \%)$ to $68.6 \%(36.1 \%+32.5 \%)$. The completion rate of hw for the 11th graders drops the most, and it follows up by the 12th graders. As a result, the decrease of studying effectiveness when transferring from offline classes to online classes is more obvious for students in 11th and 12th grade than students in 10th grade.

\section{RESULT}

Through our study, we conclude that

a.Although the experience of having online classes before the covid would help a student to get used to the new teaching mode quicker, that experience won't help students to increase their effectiveness in online classes during covid.

b.According to the data, a majority of students would keep their studying habits (either good ones or bad ones) when transferring from online classes to offline classes. Therefore, the effectiveness of online classes is pretty much based on the learning habits of students formed in offline classes.

c.The effectiveness of different genders vary from one another. Concluded from our data, female student's effectiveness in completing homework was more negatively influenced than the male's effectiveness.

d.The effectiveness of different grades vary from one another. According to the data, students in the higher grades (11th grade \& 12th grade) tend to be more negatively influenced by transferring to online classes than those students who are in lower grades (10th grade).

\section{CONCLUSION}

Online classes, as a new way of teaching that became popular in recent years, bring students and teachers the convenience of studying and teaching wherever they are comfortable with. However, the large scale of using online teaching during covid reveals many factors that lower the effectiveness of the online classes. The top four influential factors to blame for the comparative low efficiency of online classes are listed (according to participants who filled our questionnaire), and suggestions are also listed for how to improve on those deficiencies for online learning.

a.Lack of Studying environment: Students can find a quiet place like the library or the study at home to create a feeling for learning. Everyone in the library is either 
reading quietly or working on their own thing, so a student would not easily be disrupted by others. At the same time, a student should keep his phone away to limit the possibility of being pulled out of study mode.

b.Self-discipline: A student should know clearly the importance of paying attention to online learning. Listening carefully in class would definitely help a student with his completing homework and assignments. If not, a student would spend so much more time figuring out the class material after class because of the inconvenience of communication for online teaching.

c.Communicating with teachers: When facing materials a student doesn't quite understand in class, go asking the teacher right after class or on that day. If a student doesn't ask the question right away, as time goes on, the memory towards the problem would fade and the number of questions would accumulate, so that a student won't have the enthusiasm to go figure out the problem any more.

d.Technical issue: Technical support is an important factor to determine the satisfaction with online classes. [5] Some students' device are not effective while learning. [6] So the school could change from live classes to recording classes, so that the video and sound issues won't be a big problem to lower the effectiveness for online learning.

\section{REFERENCES}

[1] nambiar, deepika. The Impact Of Online Learning During COVID-19: Students' And Teachers' Perspective. 2019, Accessed 9 Aug 2021.

[2] Lin Y. Muilenburg \& Zane L. Berge(2007) Student barriers to online learning: A factor analytic study ,Distance Education,Pages 29-48.

[3] Mohammad Alawamleh\& Lana Mohannad AlTwait \& Gharam Raaft Al-Saht, 2020, The effect of online learning $\mathrm{n}$ communication between instructor and students during Covid-19 pandemic, ISSN,pages 2046-3142

[4] Awake Nopriyanto Bahason \& Wilma Ayuandiani \& Muhammad mukhram \& Aswar Rahmat,2020, Effectiveness of online learning in pandemic covid19, International jounal of Science ISSN:2722-4015

[5] COVID-19 And The Impact On Online Learning | Teachonline.Ca. 2021.

[6] Frenette, Marc. School Closures And The Online Preparedness Of Children During The COVID-19 Pandemic. feature, career et al. "Five Tips For Moving Teaching Online As COVID-19 Takes Hold". Nature.Com, 2021. 